\title{
OPINIONS OF STUDENTS AND TEACHERS ON DRUG ABUSE AMONG SENIOR SECONDARY SCHOOL IN ZARIA EDUCATION ZONE, KADUNA STATE, NIGERIA
}

\author{
${ }^{*}$ Samuel, G. A., ${ }^{2}$ George, E. O., ${ }^{3}$ Ogbu, B. N., ${ }^{4}$ Agaba, L. O. and ${ }^{5}$ Yisa, M. K.
}

\author{
${ }^{*}$ Department of Nursing Sciences, Faculty of Health Sciences, Bingham University, Karu, Nasarawa State, Nigeria \\ ${ }^{2}$ Department of Nursing Services, Ahmadu Bello University Teaching Hospital, Zaria, Kaduna State, Nigeria \\ ${ }^{3}$ Department of Nursing Science, PAMO University of Medical Sciences, Port Harcourt, Rivers State, Nigeria \\ ${ }^{4}$ Department of Nursing Service, Aminu Kano Teaching Hospital, Kano, Nigeria. \\ ${ }^{5}$ College of Nursing and Midwifery Minna, Niger State, Nigeria. \\ *Corresponding Author's E-mail: godwinatayis@gmail.com
}

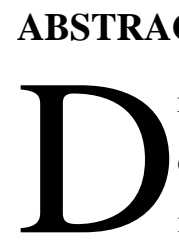

D rug abuse and dependence producing substances are widely prevalent in African countries and have continued to increase. Substances abuse, which were originally conceived as the problem of a selected few is today becoming a problem of a sizeable proportions of the world population. A cross-sectional descriptive study design was used. Using Research advisor (2006) Sampling table, 365 students and 108 teachers were sampled using stratified random sampling technique out of 3812 and 156 study populations respectively. The instrument that was used for data collection was an adapted standardized questionnaire structured by Afuwai in 2016 who worked on drug abuse on socio-emotional behavior of secondary school students in Kaduna state, Nigeria (Afuwai, 2016). Hypothesis were tested using independent sample t-test at the .05 level of significance to determine whether there is a statistically significant difference between the means of the two unrelated groups. All statistics were done using Statistical Package for Social Sciences (IBM-SPSS version 24). The study shows that all kinds of drugs are being abused by senior secondary schools' students in Kaduna State according to the opinions of the respondents with marijuana as the most commonly abuse drug while barbiturates (diazepam) is not a common abuse drug. An agglomeration of several factors influences the usage of drugs by senior secondary schools' students in Zaria education Zone of Kaduna State as there were no specific factors found. The study established that female students are more predominant on abusing drugs than their male counterparts these days.

Keywords: abuse, drug, opinions, students, teachers 


\section{INTRODUCTION}

According to United Nations Office on Drugs and Crime (UNODC) in 2010, the World Health Organization has estimated that more than 225 million individuals or one in every twenty adults have consumed an illegal drug once in the year 2010. In addition, World Health Organization (WHO) in 2014 reported that more than fifteen million persons are indulged in drug abuse and the problem of injectable drug abuse has been reported in more than 145 nations. The public health concern of drug abuse does not recognize any boundaries and affects all the persons irrespective of their socio-economic status or their belonging from a developed or developing country (Park, 2009). It is a popularly held belief that the youths of any nation are the leaders of tomorrow. They are the vehicles through which positive changes can be realized. This is why many tend to invest on the future development of its youths. Governments, parents and guardians devote a lot of time and resources in order to explore and harness the potentialities of youth. Therefore, societies that neglect the youth development may negatively affect future national development. Youth when neglected, can find escape and solace in such things as drug abuse, pick-pocketing, loitering, rape, auto-theft, truancy, delinquent or criminal act and insurgency (Radda, 2009). Adolescence is a time of experimentation, exploration, curiosity and identity search. Part of such a quest involves some risk-taking, including the use and abuse of psychoactive substances, which are the drugs that apply their major effects on the brain resulting in sedation, encouragement or change in mood of an individual (American Psychiatric Association, 2000).

Drug abuse is the harmful use of mind-altering drugs. The term usually refers to problem with illegal drugs, which also include harmful use of legal prescription drugs, such as in self-medication (Oluremi, 2012). Majority of the Nigerian adolescents ignorantly or deliberately depend on one form of drug or the other for their various daily activities (social, educational, political. Moral and others). Names of commonly abused substances and drugs include tobacco, alcohol, cocaine, heroin, Indian hemp, cannabis, opium, amphetamine, Kola nuts, coffee, aspirin, codeine, panadol, paracetamol, morphine, ephedrine, madras, caffeine, glue, barbiturates, and amphetamines. Other drug abused may include, benilyn, burukutu (local beer), cigarette, rubber solution and beer (Maikano and Aminu, 2017; Shehu etal, 2008). According to national institute on drug abuse in 2017, men are more likely than women to use almost all types of illicit drugs, and illicit drug use is more likely to result in emergency department visits or overdose, death for men than for women. "Illicit" refers to use of illegal drugs, including marijuana (according to federal law) and misuse of prescription drugs. For most age groups, men have higher rates of use or dependence on illicit drugs and alcohol than do women national institute on drugs abuse reported in 2016. However, women are just as likely as men to develop a substance use disorder and dependency (Kennedy et al. 2012). In addition, women may be more susceptible to craving (Hitschfeld et al., 2015; Fox et al., 2014; and Kennedy et al., 2012) and relapse, which are key phases of the addiction cycle.

The health of young people is a key factor in the promotion and preservation of the health of the population as a whole because it determines the overall level of population health in the short term (Tsvetkova et al., 2013). There seem to be an increasing prevalence of drug abuse amongst adolescents despite the efforts of concerned bodies to curb this menace (Adeyemo et al., 2016).

Globally, the United Nations has estimated that in 2007 between 172 and 250 million people took drugs at least once in the last 12 months and that there are between 18 and 38 million problem drug users aged 15-64 years. 
Of the total persons that used drugs in the previous year, between 134 and 190 million correspond to marijuana and other forms of cannabis, between 16 and 51 million to amphetamine group and between 12 and 24 million are ecstasy and ATS users in East and South East Asia, of methamphetamines in North America, of amphetamines in Europe and in the Near and Middle East. As for opiates, between 15 and 21 million reported their intake with higher rates found along the trafficking routes close to Afghanistan, in 2006 it was estimated that some 11 million were taking heroin, with an increase in Asia, and no differences in other parts of the world. In 2007 between 16 and 21 million reported the intake of cocaine (Ghodse et al., 2011).

Drug abuse and dependence producing substances are widely prevalent in African countries and around the world; and have continued to increase. This is a problem whose effect cut across the individual, the family and the society at large. Substance abuse, which was seen before as the problem of a selected few people is today becoming a problem of a sizeable proportion of the people in the world. The problem is so grave that it has extended beyond the usual characteristic profile of abusers being male, adult, and urban-based as perceived before to now include females, youngsters and those who live in rural areas of the world. Over the past year alone, nearly $15 \%$ of the adult population in Nigeria (around 14.3 million people) reported a "considerable level" of use of psychoactive drug substances-it's a rate much higher than the 2016 global average of 5.6\% among adults. The survey was led by Nigeria's National Bureau of Statistics (NBS) and the Center for Research and Information on Substance Abuse with technical support from the United Nations Office on Drugs and Crime (UNODC) and funding from the European Union (Yomi, 2019).

A World Health Organization (WHO) report noted that alcohol abuse results in 3million deaths annually across the world, Nigeria inclusive; this represent $5.3 \%$ of all deaths (WHO, 2018). Apart from cannabis misuse, there is a growing abuse of synthetic drugs, which were once strange to the Nigerian society. Amphetamine, methamphetamine, cocaine, heroin, paint thinner, glue, cough syrup made with codeine, cement and animal excreta are being widely abused. According to Punch Newspaper in 2016, between 2010 and 2012, six methamphetamine factories were discovered in Delta and Lagos states, said the National Drug Law Enforcement Agency (NDLEA). According to American Addition Centre in 2020 and National Institute on Drugs Abuse in 2018, the more often drugs are used the more they will impact brain chemicals and circuitry which can lead to drug dependence and withdrawal symptoms when the drugs process out of the body. Drug cravings, dependence, and withdrawal symptoms, coupled with a loss of control over use, are signs of addiction and as such more of the substance is then needed in order to produce desired effects; that are a need for markedly increased amounts of the substance to achieve intoxication or desired effect. When this happens, any effort to stop or reduce the use of this substance would cause withdrawal symptoms to occur (Antai-Otong, 2008). It is based on the above statements that the researcher intends to carry out a study on the prevalence and factors responsible for drugs abuse among senior secondary school students in Zaria education zone of Kaduna state.

The following specific objectives were formulated for the study:

1. To identify the common type of drugs being abused among senior secondary school students of Kaduna state.

2. To discover the factors responsible for influencing students to abuse drugs in senior secondary schools of Kaduna State. 
3. To inquiry about the frequency of drug abuse among genders in senior secondary school students in Kaduna state.

The following null hypotheses were formulated and tested in this study at the 0.05 level of significance:

i. There are no specific drugs that are abused by senior secondary school students in Kaduna state.

ii. There are no factors that influence students' usage of drugs in senior secondary schools of Kaduna state.

iii. There is no significant difference between the frequency of drug abuse among the gender in senior secondary school students in Kaduna state.

The study will be delimited to opinions of students and teachers on drug abuse among senior secondary school in Zaria education zone, Kaduna State, Nigeria.

\section{MATERIALS AND METHOD ETHICAL CONSIDERATION}

Ethical clearance was granted by Quality Assurance Authority Zaria Division, Kaduna State Ministry of Education, Science and Technology on the 10th October, 2019 in a letter with reference number: ZA/ZON/G.198/VOL. 1/262 to conduct the study.

\section{RESEARCH DESIGN}

This study employed a cross-sectional descriptive study design which was used to collect information about the opinions of students and teachers on drug abuse among senior secondary school in Zaria education zone, Kaduna State, Nigeria in 2019

\section{SAMPLE SIZE AND SAMPLING TECHNIQUE}

The sample size for this study was determined using the Research Advisor table of recommendation of 2006 (Research Advisory, 2006). A Study population of 3812 students of senior secondary schools and 156 teachers respectively were used (Kaduna State Ministry of Education, 2019). A total of three hundred and sixty five (365) students and 108 teachers were selected from five randomly selected schools within Zaria division of Kaduna state as follows: Out of the following Secondary schools in Zaria Education Zone:- Government commercial college Muchia, Government Secondary School (GSS) Chindit (Senior), Angwangodo, Government Girls Secondary School (GGSS) Chindit (Senior), Sabon Gari, Government Secondary School (GSS) Aminu, and Government Secondary School (GSS) Muchia. The following five Schools were selected randomly: Government commercial college, Government Secondary School (GSS) Chindit (Senior), Government Secondary School (GSS) Muchia, Government Secondary School (GSS) Aminu and Government Girls Secondary School (GGSS) Chindit (Senior) respectively. From the five selected public Secondary Schools, stratified sampling technique was used to select the senior students proportionately from each stratum depending on the population of the stratum (Senior Secondary (SS) 1, SS 2 and SS 3). Also, from the respective schools, one hundred and eight (108) teachers were sampled proportionately to the total number of teachers in each school using simple random sampling technique. 


\section{METHOD OF DATA ANALYSIS}

Statistics were presented in Mean and standard deviation and a modified three point-scale rating of Likert format was used. Ranging from agree (A), Neutral (N) and disagree (D); with scores of 3, 2, and 1 respectively. Hypotheses were tested using an independent sample t-test at the .05 level of significance to determine whether there is a statistically significant difference between the means of the two unrelated groups. All statistics were done using Statistical Package for Social Sciences (IBM-SPSS version 24).

\section{INSTRUMENTATION}

The instrument that was used for data collection was an adapted standardized questionnaire structured by Afuwai in 2016 who worked on drug abuse on socio-emotional behavior of secondary school students in kaduna State, Nigeria (Afuwai, 2016). The data from the pilot study was analyzed using Cronbach's alpha method selected from the Statistical Package for Social Sciences (IBM-SPSS version 24) for reliability co-efficient to determine the internal consistency of the instruments. The reliability index of .804 was found for the first administration and .813 for the second administration of the instrument.

\section{DECLARATION OF INTEREST}

The authors declare that they have no known competing financial interests or personal relationships that could have appeared to influence the work reported in this paper.

\section{RESULTS}

Table 1: Opinion of Respondents on Drugs Commonly Abused Among Senior Secondary School Students

S/N Students Teachers

\begin{tabular}{|c|c|c|c|c|c|c|c|c|c|c|}
\hline & & $\mathbf{A}$ & $\mathbf{N}$ & D & $\mathbf{A}$ & $\mathbf{N}$ & D & Mean & Std. Dev & Remark \\
\hline 1 & Alcohol & 205 & 45 & 99 & 38 & 26 & 24 & 2.23 & 0.86 & Agreed \\
\hline 2 & $\begin{array}{l}\text { Marijuana (Weewee, } \\
\text { ganja) }\end{array}$ & 271 & 31 & 47 & 75 & 7 & 6 & 2.71 & 0.63 & Agreed \\
\hline 3 & Cigarette (Taba) & 295 & 14 & 40 & 62 & 16 & 10 & 2.66 & 0.67 & Agreed \\
\hline 4 & $\begin{array}{l}\text { Cough syrup (e.g. } \\
\text { Tutolyn, benylin) }\end{array}$ & 227 & 45 & 77 & 69 & 10 & 9 & 2.56 & 0.74 & Agreed \\
\hline 5 & $\begin{array}{l}\text { Barbiturates } \\
\text { (Diazepam) }\end{array}$ & 139 & 122 & 88 & 14 & 36 & 38 & 1.94 & 0.76 & Disagreed \\
\hline & Cumulative & & & & & & & (2.42) & (1.83) & \\
\hline
\end{tabular}

Benchmark: Mean $\geq 2.00=$ Agree; Mean $<2.00=$ Disagree; $\mathrm{A}=$ Agree; $\mathrm{N}=$ Neutral; $\mathrm{D}=$ Disagree 
Table 1 show the opinion of respondents on drugs commonly abuse by senior secondary school students in Kaduna. The cumulative mean responses of all the items is 2.42 which is greater than the benchmark mean of 2.00 with the standard deviation value of 1.83 implying that their responses were remarkable. From the table, it was perceived that majority of the respondents were of the opinion that marijuana (wewee, ganja) was the most commonly abused drug among senior secondary school students as this item attracted the highest mean response of 2.71 and standard deviation of 0.63 with details showing that 346 respondents were in agreement while 53 respondents disagreed to this view. Although the cumulative mean response is above the bench mark mean of 2.00, item (5) was however disagreed to, implying that barbiturates (diazepam) is not a common drug abuse by students in senior secondary schools in Zaria education Zone, Kaduna State. This might not be unconnected with having easy access to other drugs mentioned aside barbiturates. To test whether or not their responses was significant, their opinions were subjected to an independent samples t-test at 0.05 level of significance

Table 2: Opinion of Respondents on Factors Responsible for Influencing Drug Abuse Among Senior Secondary School Students

S/N Students Teachers

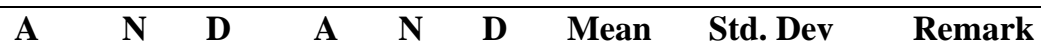

\begin{tabular}{lllllllllll}
\hline 1 & Stress & 169 & 61 & 119 & 33 & 24 & 31 & 2.08 & 0.88 & Agreed \\
2 & Parents/ family & 167 & 48 & 134 & 24 & 26 & 38 & 1.97 & 0.88 & Disagreed \\
& influence & & & & & & & & & \\
3 & Peer pressure & 253 & 45 & 51 & 74 & 6 & 8 & 2.67 & 0.67 & Agreed \\
4 & Poverty & 195 & 41 & 113 & 36 & 23 & 29 & 2.16 & 0.89 & Agreed \\
5 & Availability of drug & 181 & 64 & 104 & 51 & 15 & 22 & 2.28 & 0.87 & Agreed \\
& outlet & & & & & & & & & \\
& Cumulative & & & & & & & &
\end{tabular}

Benchmark: Mean $\geq 2.00=$ Agree; Mean $<2.00=$ Disagree; A= Agree; $\mathrm{N}=$ Neutral; $\mathrm{D}=$ Disagree

Table 2 shows the opinion of respondents on factors responsible for influencing drug abuse among senior secondary school students in Kaduna State. The cumulative mean responses of all the items is 2.23 which is greater than the benchmark mean of 2.00 with the standard deviation value of 0.84 implying that their responses were remarkable. From the table, it was perceived that peer pressure is the major factor responsible for influencing drug abuse among senior secondary school students with the highest mean response of 2.67 and standard deviation of 0.84 with details showing that 327 respondents were in agreement while 59 respondents disagreed to this view. Parents/family influence was disagreed to, as a factor responsible for influencing drug abuse among senior secondary school students in Kaduna State with a mean of 1.97 which is less than the benchmark mean of 2.00. To test whether or not their responses was significant, their opinions were subjected to an independent sample t-test at 0.05 level of significance. 
Table 3: The Opinion of Respondents on The Frequency of Drug Abuse Among Genders in Senior Secondary School Students in Kaduna State

\begin{tabular}{|c|c|c|c|c|c|c|c|c|c|c|}
\hline \multirow[t]{2}{*}{$\mathbf{S} / \mathbf{N}$} & & \multicolumn{3}{|c|}{ Students } & \multicolumn{6}{|c|}{ Teachers } \\
\hline & & $\mathbf{A}$ & $\mathbf{N}$ & D & $\mathbf{A}$ & $\mathbf{N}$ & D & Mean & Std. Dev & Remark \\
\hline 1 & Male & 58 & 58 & 233 & 10 & 26 & 52 & 1.51 & 0.73 & Disagreed \\
\hline 2 & $\begin{array}{l}\text { Female } \\
\text { Cumulative }\end{array}$ & 317 & 6 & 26 & 78 & 4 & 6 & $\begin{array}{l}2.83 \\
(2.17)\end{array}$ & $\begin{array}{l}0.54 \\
(0.64)\end{array}$ & Agreed \\
\hline
\end{tabular}

Benchmark: Mean $\geq 2.00$ = Agree; Mean $<2.00$ = Disagree; A=Agree; $\mathrm{N}=$ Neutral; $\mathrm{D}=$ Disagree

Table 3 shows the opinion of respondents on the prevalence of drug abuse among genders in senior secondary school students in Kaduna. The cumulative mean responses of all the items is 2.17 which is greater than the benchmark mean of 2.00 with the standard deviation value of 0.64 implying that their responses were notable. From the table, it was observed that majority of the respondents were of the opinion that female secondary school students are more predominant on drug abuse than their male counterparts these days as this item attracted the highest mean response of 2.83 and standard deviation of 0.54 with details showing that 395 respondents were in agreement while 32 respondents disagreed to this view. Although the cumulative mean response is above the bench mark mean of 2.00, items (1) was however disagreed to, implying that drug abuse is more predominant among female students. To test whether or not their responses were significant, their opinions were subjected to an independent sample t-test at 0.05 level of significance.

Null Hypothesis One: There is no significant difference in the opinion of teachers and students on specific drugs that are abuse by senior secondary school students in Kaduna state.

Table 4: T-test concerning the opinions on sspecific Drugs Abuse by Secondary School Students in Kaduna State

\begin{tabular}{|c|c|c|c|c|c|c|c|c|}
\hline Variables & $\mathbf{N}$ & $\bar{X}$ & S.D & df & t-cal & t-crit & $p$ & Remark \\
\hline Teachers & 88 & 11.91 & 2.08 & & & & & \\
\hline Students & 349 & 12.25 & & 435 & 1.03 & 1.98 & 0.30 & Not Sig. \\
\hline
\end{tabular}


Not Significant at $\mathrm{P}>0.05 \quad$ Key: $\mathrm{N}=$ Sample Size; $\overline{\mathrm{X}}=$ Mean; $\mathrm{SD}=$ Standard Deviation; df $=$ Degree of Freedom $\mathrm{t}$-cal $=\mathrm{t}$ calculated t -crit.$=\mathrm{t}$ critical; $\mathrm{Sig}=$ Significant

The independent samples t-test in Table 4 shows that there is no significant difference in the opinions of teachers and students concerning the specific drugs abuse by senior secondary school students in Kaduna State. This is because the calculated p-value of 0.30 is greater than 0.05 level of significance and the calculated t-value of 1.03 is less than the $\mathrm{t}$-critical value of 1.98. Therefore, the null hypothesis which states that there is no significant difference in the opinion of teachers and students on specific drugs that are abuse by senior secondary school students in Kaduna State is hereby retained. This is an indication that the respondents basically are of the opinions that all the drugs identified in the study are being abuse by senior secondary school students in Kaduna State at different levels these days.

Null Hypothesis Two: There is no significant difference in the opinion of teachers and students on the factors that influence students' usage of drugs in senior secondary schools of Kaduna state.

Table 5: T-test regarding opinions of teachers and students on the factors that influence Students' usage of Drugs in Senior Secondary Schools of Kaduna State

\begin{tabular}{|c|c|c|c|c|c|c|c|c|}
\hline Variables & $\mathbf{N}$ & $\bar{X}$ & S.D & df & t-cal & t-crit & $p$ & Remark \\
\hline Teachers & 88 & 11.02 & 2.44 & & & & & \\
\hline Students & 349 & 11.27 & & 435 & 0.76 & 1.98 & 0.45 & Not Sig. \\
\hline
\end{tabular}

Not Significant at P>0.05 Key: N = Sample Size; $\bar{X}=$ Mean; SD = Standard Deviation; df = Degree of Freedom, $\mathrm{t}$-cal = $\mathrm{t}$ calculated; $\mathrm{t}$-crit. $=\mathrm{t}$ critical; Sig = Significant

The independent samples t-test in Table 5 shows that there is no significant difference in the opinion of teachers and students with regards factors that influence students' usage of drugs in senior secondary schools of Kaduna State. This is because the calculated p-value of 0.45 is greater than 0.05 level of significance and the calculated t-value of 0.76 is less than the t-critical value of 1.98. Therefore, the null hypothesis which states that there is no significant difference in the opinion of teachers and students on the factors that influence students' usage of drugs in senior secondary schools of Kaduna State is hereby retained. This implies that the respondents are of the opinion that there is no specific factor that influences the usage of drugs by senior secondary school students in Kaduna State but an agglomeration of several factors. 
Null Hypothesis Three: There is no significant difference between the frequency of drug abuse among male and female senior secondary school students in Kaduna state.

Table 6: T-test concerning opinions on the frequency of Drug Abuse among Male and Female Senior Secondary Schools Students in Kaduna State

\begin{tabular}{|c|c|c|c|c|c|c|c|c|}
\hline Variables & $\mathbf{N}$ & $\bar{X}$ & S.D & df & t-cal & t-crit & $p$ & Remark \\
\hline Male & 211 & 5.82 & 2.97 & & & & & \\
\hline \multirow[t]{2}{*}{ Female } & 226 & 5.90 & & 435 & 0.25 & 1.98 & 0.81 & Not Sig. \\
\hline & & & 3.53 & & & & & \\
\hline
\end{tabular}

\section{Not Significant at P>0.05, Key: $\mathbf{N}=$ Sample Size; $\bar{X}$ = Mean; SD = Standard Deviation; $d f$ = Degree of Freedom, $\mathrm{t}$-cal $=\mathbf{t}$ calculated; $\mathrm{t}$-crit $\mathbf{=} \mathbf{t}$ critical; $\mathbf{S i g}=$ Significant}

Table 6 shows that there is no significant difference in the opinion of respondents concerning the frequency of drug abuse among male and female senior secondary schools' students in Kaduna State. Reason being that the calculated $\mathrm{p}$-value of 0.81 is greater than 0.05 level of significance; and the calculated t-value of 0.25 is less than the t-critical value of 1.98. Therefore, the null hypothesis which states that there is no significant difference between the frequency of drug abuse among male and female senior secondary schools' students in Kaduna State is hereby retained. This is a perceived indication that both male and female senior secondary schools' students are involved in drug abuse.

\section{DISCUSSION}

This study revealed that basically all the drugs identified in the study are being abuse by senior secondary schools' students in Kaduna State these days. Although from the mean scores of the respondents, it was observed that majority of the respondents were of the opinion that marijuana (wewee, ganja) is the most commonly abuse drug among senior secondary schools students as this item attracted the highest mean response of 2.71 and standard deviation of 0.63 with details showing that 346 respondents were in agreement while 53 respondents disagreed to this view. It also implied that barbiturates (diazepam) are not a common drug abuse by students in senior secondary schools in Zaria education Zone, Kaduna State.

This study finding is in line with a study in the United States of America where it was revealed that half of adolescents have used an illicit drug by the $12^{\text {th }}$ grade and most commonly used illicit drug is marijuana (Johnston $e t$ al., 2012). In the opinion of teachers and students, there is no specific drugs abuse by senior secondary schools' students ( $\mathrm{p}$-value of $0.30>0.05$ level of significance)

The study based on the opinions of the respondents revealed also that stress, poverty, peer pressure and availability of drugs are among factors that influenced students abuse of drugs in senior secondary schools. Although 
the respondents disagree with the fact that parent or family influence can be a factor predisposing students to abuse drugs. The study retained the null hypothesis which states that there is no significant factors that influence students' usage of drugs in senior secondary schools of Kaduna State (p-value of 0.45 is greater than 0.05 level of significance). This implies that no specific factor influences the usage of drugs by senior secondary schools students in Kaduna State but an agglomeration of several factors according to the respondents.

This study established that from the opinion of the teachers and students, female students are abusing drugs more than their male counterpart. This may be due to the fact that there is an alarming rise in the number of females who abuse drugs these days and as such the gap to the male counterpart has been bridged. According to United Nations Office on Drugs and Crimes in 2018. "The majority of people who use drugs are men, but women have specific drug use patterns. The prevalence of non-medical use of opioids and tranquillizers by women remains at a comparable level to that of men, if not actually higher. While women may typically begin using substances later than men, once they have initiated substance use, women tend to increase their rate of consumption of alcohol, cannabis, cocaine and opioids more rapidly than men as well as rapidly develop drug use disorders." If one looks at rate of escalation of drug use, however, women tend to increase their rate of consumption of alcohol, marijuana, opioids and cocaine more rapidly than men (Lynch et al., 2002). Similarly, gender differences in marijuana use, the most commonly used illicit substance among adolescents, appear to be changing. Specifically, for the casual user, gender differences are narrowing (Sarigiani et al., 1999). The study retained the null hypothesis which states that there is no significant difference between the frequency of drug abuse among male and female secondary school students in Kaduna State (p-value of $0.81>0.05$ level of significance). This is an indication that both male and female secondary school students are involved in drug abuse.

\section{CONCLUSION}

Most drugs (alcohol, marijuana, cough syrup, barbituarate, and cigarette) are being abused by senior secondary schools' students in Kaduna State according to the respondents. Marijuana is perceived as the most commonly abused drug among senior secondary schools' students while barbiturates (diazepam) is not a common drug abused by students in senior secondary schools in Zaria education Zone, Kaduna State. There is no specific factor influencing the usage of drugs by senior secondary schools' students in Zaria education Zone of Kaduna State but an agglomeration of several factors. Female students were more predominant or bridging the gap on drug abuse than their male counterparts nowadays.

\section{REFERENCES}

Adeyemo, F.O., Ohaeri, B., Pat, U. and Okpala, O. O. (2016). Prevalence of Drug Abuse Amongst University Students in Benin City, Nigeria: Public Health Research 6(2): 31-37 DOI: 10.5923/j.phr.20160602.01

Afuwai E.N. (2016). Drug Abuse on Socio-Emotional Behaviour among Secondary School Students in Kaduna State, Nigeria. Unpublished.

American Psychiatrist Association (2000). Diagnostic and Statistical manual of mental disorder. 4th ed, Washington D.C., United States of America. 
Antai-Otong, D. (2008). Psychiatric Nursing: Biological and Behavioral Concepts. 2nd ed. Canada: Thompson Delmar

Fox, H.C., Morgan, P.T. and Sinha, R. (2014). Sex differences in guanfacine effects on drug craving and stress arousal in cocaine-dependent individuals. Publication of American College of Neuropsychopharmacology 39(6):15271537. doi:10.1038/npp.2014.1

Ghodse, H., Herrman, H., Maj, M. and Sartorius, N. (2011). Substance Abuse Disorders: Evidence and Experience, 1st ed, United Kingdom: John Wiley \& Sons Ltd., ISBN: 978-0-470-74510-6

Hitschfeld, M.J., Schneekloth, T.D. and Ebbert, J.O. (2015). Female smokers have the highest alcohol craving in a residential alcoholism treatment cohort. Drug Alcohol Dependency 150:179-182. doi:10.1016/j.drugalcdep.2015.02.016

Johnston, L. D., O'Malley, P. M., Bachman, J. G. and Schulenberg, J. E. (2012). Monitoring the Future, national results on adolescent drug use, 1975- 2009: Volume II, College Students and adults ages 19 - 50 ( National Institute of Health Publication No. 10-7585). Bethesda, MD: National institute on drugs abuse.

Kaduna State Ministry of Education (2019). Report: 2018/2019 academic session record, Zonal office, Zaria.

Kennedy, A.P., Epstein, D.H., Phillips, K.A. and Preston, K.L. (2012). Sex differences in cocaine/heroin users: drug-use triggers and craving in daily life. Drug Alcohol Dependency 132(1-2):29-37. doi:10.1016/j.drugalcdep.2012.12.025

Lynch, W.J., Roth, M.E. and Carroll, M.E. (2002). Biological basis of sex differences in drug abuse: preclinical and clinical studies. Psychopharmacology 164:121-137. [PubMed]

Maikano, M. and Aminu, M.D. (2017). The Influence of Substance Abuse on Youths' Prospects in Nigeria and the Way Forward. Advances in Psychology and Neuroscience 2(2-1): 15-20.

Oluremi, D. F. (2012). Drug Abuse among Nigerian Adolescents strategies for counselling. Journal of International Social Research. 5(20):342-347.

Park, K. (2009). Medicine and social sciences. In: Park K, (eds). Textbook of Preventive and Social Medicine. 20th ed., Jabalpur: Banarsidas Bhanot, pp 608-609.

Radda, S. I. (2009), "Youth Counter-Culture: Studies in Cultural Sociology,"in Abdullahi, Randolph WM, Stroup-Benham C, Black SA, Markides KS. Alcohol use among Cuban-Americans, Mexican Americans, and Puerto Ricans. Alcohol Health Research World. 1998;22:265-269. [PubMed]

Research advisory (2006). Sample size table: The Research Advisors (http://research-advisors.com)

Sarigiani, P.A., Ryan, L. and Petersen, A.C. (1999). Prevention of high-risk behaviors in adolescent women. Journal of Adolescent Health 25:109-119. [PubMed]

Shehu, A. U. and Idriss, S.H. (2008). Marijuana smoking among secondary School Students in Nigeria; factors responsible and effects on academic performance. Annals of African Medicine 7 (4): 175-179.

Tsvetkova, L. A. and Antonova, N.A. (2013). The Prevalence of Drug use among University Students in St. Petersburg, Russia. Psychology in Russia: State of the Art 6 (1):86-94

WHO (2018). Fact sheet: Global status report on alcohol and health. https://www.who.int/news-room/factsheets/detail/alcohol 
Yomi, k. (2019). Nigerian drugs abuse: A national survey has confirmed the massive scale of Nigeria's drug problem. Quartz African weekly brief , January 31, 2019. https://qz.com/africa/1538843/nigeria-drug-abuse-14-millionadults-use-drugs/ 